\title{
2D-CFD Analyses of Flow Controlling Plates on Gable Roof Geometry Cross-Sections for Light Air to Strong Breeze Wind Speed Classifications- an Unsteady RANS Approach
}

\author{
Kasra Amini $^{1,2^{*}} \mathbb{D}$, Alireza Mani ${ }^{3}$ \\ ${ }^{1}$ Faculty of Mechanical Engineering, RWTH Aachen University, Aachen, Germany \\ ${ }^{2}$ Institute of Aircraft Propulsion Systems (ILA), University of Stuttgart, Stuttgart, Germany \\ ${ }^{3}$ Department of Mechanical Engineering, Sharif University of Technology, Tehran, Iran \\ E-mail: kasra.amini@rwth-aachen.de
}

Received: 27 November 2019; Revised: 04 February 2020; Accepted: 29 February 2020

\begin{abstract}
The flow field analysis has been numerically performed on the effectiveness of a flow control mechanism called the Flow Controlling Plate (FCP) on buildings. For this purpose, the gable roof geometry has been considered as a common urban element in the western residential architecture. As the justification step towards the functionality of the concept of FCPs, the 2D numerical investigation of the flow field under the realistic assumptions of atmospheric boundary layer profiles for the spectrum ranging from the so-called light air to strong breeze wind speed classifications have been performed. The CFD (Computational Fluid Dynamics) field calculations have been conveyed as an unsteady case for the flow around a bluff body, using RANS (Reynolds Average Navier-Stokes) averaging methods targeting a solution of Navier-Stokes equations of the fluid flow. The results have proven the hypotheses of the contribution of the FCPs on preventing the flow separation on a partial region of the surface and improving the boundary layer development on the rest of the gable roof facades, which have led to a drastic reduction in the convective heat transfer coefficient as well as the drag force exerted on the roof.
\end{abstract}

Keywords: flow control, streamlining, flow controlling plates (FCPs), gable roof, computational fluid dynamics (CFD), flow separation

\section{Nomenclature}

$\begin{array}{ll}\text { Latin Letters } \\ \mathrm{U} & \text { Inlet wind velocity } \\ \mathrm{U}^{*} & \text { Friction velocity } \\ \mathrm{z} & \text { Height } \\ \mathrm{z}_{0} & \text { Aerodynamic roughness length } \\ \mathrm{D} & \text { Cross-diffusion term } \\ \vec{F} & \text { External body force } \\ \vec{G} & \text { Generation } \\ \mathrm{H} & \text { Energy }\end{array}$

Copyright (C2020 Kasra Amini, et al.

DOI: https://doi.org/10.37256/gbce.112020156

This is an open-access article distributed under a CC BY license

(Creative Commons Attribution 4.0 International License)

https://creativecommons.org/licenses/by/4.0/ 


\begin{tabular}{ll} 
I & Unit tensor \\
J & Mass flux \\
$\mathrm{k}$ & Thermal conductivity \\
$\mathrm{p}$ & Static pressure \\
$\mathrm{S}$ & Source term \\
$\mathrm{v}$ & Velocity component \\
$\mathrm{T}$ & Temperature \\
Y & Dissipation due to turbulence \\
Greek Letters \\
$\kappa$ & Von Karman coefficient \\
$\mu$ & Dynamic viscosity \\
$\rho$ & Density \\
$\tau$ & Shear stress \\
$\Gamma$ & Effective diffusivity \\
Abbreviations \\
FCP & Flow Controlling Plates \\
BR & Blockage Ratio \\
ABL & Atmospheric Boundary Laye \\
CHTC & Convective Heat Transfer Coefficient \\
FAR & Floor Area ratio \\
Subscripts & \\
m & Mass \\
$\omega$ & Specific dissipation rate \\
Eff & Effective \\
I & Light air \\
III & Gentle breeze \\
IV & Moderate breeze \\
V & Fresh breeze \\
VI & Strong breeze \\
W & Width \\
H & Height \\
\hline &
\end{tabular}

\section{Introduction}

The ever-raising trend of wind flow interactions with urban structures and houses in terms of severe damage in cases of hurricane and storm, as well as rather milder effects such as general potential for high amounts of heat loss through convective capacity of the flow field around the houses, in cases of normal and moderate wind velocities, have caused attention towards the field of building aerodynamics and wind engineering in a more general terminology.

Among numerous works addressing wide spectrums of the topics of interest in the field of building aerodynamics, the following serves as a brief literature survey mostly relevant to the subject matter discussed in the current manuscript.

Castro and Robins [1] presents the results on a surface-mounted cube as the uniform turbulent flow bypasses it. As the most urban geometries, demanded by the constraints in their architectural design, are somehow the variations of cubic shapes, the flow field investigated around the cube geometry installed on a flat surface gives relevant results on the aerodynamics of buildings and urban elements.

Cermak [2] presents topics in the applications of fluid mechanics for the branch of aerodynamics dealing with the industrial and urban fluid configurations; namely, the wind engineering.

The specific case of a $6 \mathrm{~m}$ cube submerged in the wind flow and the corresponding pressure exerted on the body has been presented in Richards et al. [3], while Richards and Hoxey [4] focuses directly on the wind loads exerted on the top surface of the said cubic geometry. And the more specific investigation on the pressure distributions on a cubic building 
is presented in $[5,6]$.

As the flow field around buildings, and in other words induced by the geometry of the buildings, is strongly influential on the convective heat transfer behavior of the building, Mirsadeghi et al. [7] reviews the distinct models proposed for the convective heat transfer models in building energy simulation programs. Whereas, the experimental aspects of the heat transfer in turbulent flow over wall mounted cubes is analyzed in Meinders [8].

Defraeye et al. [9] uses CFD modeling as well as existing correlations to address the matter of convective heat transfer coefficient for exterior building surfaces, while the more direct study of the heat and mass transfer on the vertical walls of a street canyon is reported in Saneinejad et al. [10], and the case of windward building facades has been addressed numerically targeting the analysis of forced convective heat transfer coefficient under the influence of building geometrical configuration [11].

Blocken et al. [12] reports on the application of Computational Fluid Dynamics in the more general field of building performance simulations for the outdoor environments. Also, the matter of pedestrian wind comfort and safety in urban areas has been tackled using CFD on the case study for the Eindhoven University campus [13]. Tominaga et al. [14] presents guidelines for the practical applications requiring the CFD implementation to analyze the pedestrian wind environment around buildings of distinct geometries.

Wind climate in regard to the urban geometries is addressed in Bottema [15], and Amini et al. [16] uses CFD for verification of a novel flow control system implemented on a smart solar house in order to minimize the convective heat transfer rate, as well as gaining a reduction in the drag force exerted on the structure by the upstream wind. The more detailed investigation on the enhancement of the control algorithm for the mentioned smart flow control mechanism is presented in Amini et al. [17].

Shi et al. [18] and Reiter [19] consider the pedestrian comfort aspects of urban aerodynamics from the view point of urban planning and design. Aregger and Glaus [20] covers flow related issues on high-rise building and urban architecture. Issues on the effects of wall function roughness modification for the atmospheric boundary layer for the case of the passage between sets of parallel buildings has been addressed in Blocken et al. [21], whereas the wind condition present in passages between two long narrow perpendicular buildings is presented in Blocken et al. [22]. Stathopoulos [23] presents insight on the pedestrian level winds and urban comfort criteria, as Ai and Mak [24] investigates the effects of inhomogeneous atmospheric boundary layer on an isolated building using CFD.

The current manuscript investigates the proposed flow control mechanism, named Flow Controlling Plates (FCPs) by the authors, based on the hypothesis of its contribution in increasing the thermal performance of the building by decreasing the convective heat transfer coefficient, as well as positive influences on the wind loads on the whole structure of the building as well as local enhancements on the rigidity of tiles and elements installed on the facades. As the analyses have been pursued numerically, the stepwise presentation of the CFD procedure is covered in detail, after the case narrative including the design philosophy and specifications of the FCPs mechanism, in the following chapters. The flow analysis is to be following the methodology section, including the results and their corresponding discussions.

\section{Case narrative}

\subsection{Design philosophy}

The present research addresses the general building aerodynamics problem existing by the traditional architectural form; namely gable roof. The mentioned motif used in all sorts of buildings with different functionalities as well as distinct sizes, consists of a rectangular base with diverse aspect ratios, risen to an essential height according to the function of the building, and a set of oblique ceiling surfaces. These surfaces may coincide on a point, a line or a horizontal surface. The case, where this coincidence occurs on a horizontal line is called a "gable roof" and is the concentration point of this manuscript.

However convenient from the architectural and structural point of view, gable roofs are associated with a certain list of problems regarding the flow field around them. A sudden change of slope at the coincidence line on the top of the gable roof makes it impossible for the airflow to be attached to the surface in almost all practical flow regimes around houses, since the Re number exceeds that of required by the creeping flow premises. The separation of the flow at the exact location of the sharp edge on the top leads to the severe fluctuating flow region on the lee-side leaving it in the 
wake of the gable roof. Due to the large circulation radii of the local wake region with respect to the characteristic length of the roof surface in the direction of the flow, in most cases the flow does not go through a reattachment, hence leaving the entire lee-side in the wake which is afterwards merged with the general wake region behind the geometry, generated due to the overall cubic form of the house. This is often accompanied by the $3 \mathrm{D}$ flow phenomena in the span wise direction; such as cross flow, roof tip vortices, back flow and other secondary flow conditions fed from the side and back facades, and non-aligned upstream wind orientations, all of which add up to the instability of the boundary layer.

As consequents, a higher convective heat coefficient is foreseen, which leads to heat losses on the attic and all inner areas in contact and in the same thermal zone with the gable roof. That is also emphasized by the fact that the attic rooms are already equipped with a lower level of isolation compared to the other areas of the building, which makes the case even more intense. Although adding more insolation layers may seem like a valid solution, however reducing the heat absorption potential in the external flow field tackles the problem at its core, in a more cost-effective manner.

On the other hand, the aforementioned flow phenomena lead to several other difficulties, among which negative pressure gradient on the leeward gable surface is of great importance. The consequents of this reverse pressure gradient are two fold; first it increases the fraction of drag force, known as the pressure drag, applied on the structure, and second; due to lack of proper amount and functionality of the adhesives the clay roof tiles may come off and fall, which as a pragmatic problem has even made its way into the urban and building codes.

Pedestrian comfort counts also as a crucial problem to be addressed by streamlining the flow around urban bodies, such as buildings, bridges, and so on. According to the above discussions on the large separation area on the lee-side of the gable roofs, and the secondary effects such as spatial blending of the roof separated flow with the wake flow behind the body, leads to an intense unsteady wake-type flow downstream of such buildings, which has a significant role in disturbing the pedestrian comfort, as well as degeneration of the vegetation texture.

In order to address the mentioned problem, the flow over the gable roof should be controlled in a way to minimize the influence of sharp redirection in the geometry at the top of the gable. For that matter a thin flat plate parallel to the gable roof at the lee-side, namely the FCP, has been suggested by the current research. Having such a guiding plate causes the flow to be attached to the surface and prevents the separation, regardless of the convergent or divergent geometrical slope, which for the case of lee-side gable roof is divergent. Formerly 3D flow will also be limited to a semi-2D flow similar to that of the channel flow. Boundary layer starts to grow on both surfaces; roof and under the FCP, till it reaches the fully developed condition and continues with constant thickness afterwards.

The implementation of such mechanism (FCPs), could be multi-fold. The flow separation will be delayed as the structure dictates the attached flow on the most, and the most critical, parts of the gable roof lee-side. This will firstly reduce the convective heat transfer coefficient in the flow field around the mentioned part of the geometry. As the commonly practiced procedures of such urban architectures is mostly with a weaker than average thermal isolations in the attic, the implementation of FCPs will provide a notable advantage.

Also, since the prevention or even delay (either local or temporal) in the flow separation will decrease the pressure gradient between the stagnation point (more practically the pressure-side of the gable geometry), and the separation bubble or the wake regions. Having said that, the drag force exerted on the body and foundation of the building is reduced drastically. This could also be characterized as a local pressure difference leading to either disassembling the roof tiles, in cases of stronger wind conditions such as storms or hurricanes, which is due to the higher pressure gradient on the local tiles position, on and under the tiles and attic roof structure.

The realization of the concept is possible in two ways. One way is to consider the overall dominant wind direction of the site, decide on the leeside, and install the fixed configuration of an FCP on said roof side. Second way would be to have it adjustable for the optimized offset distance, or the basic on and off modes, on some mechanical mechanism, such as hydraulic jacks and pumps. For the latter one, one concern would be the energy consumption of the concept which claims to have an advantage in terms of heat losses and energy efficiency. However, since the velocity ranges for the adjustments of the FCP are extremely low and the number of the so-called adjustments are not high throughout the month, the power needed for this procedure are much lower than the energy gain the system will provide.

\subsection{Geometry}

The case considered for this study is a classic gable roof on a one-story high building of $3 \mathrm{~m}$ height added by a 
55-degree gable slope on each side, on a $6 \mathrm{~m}$ wide lot as the width of the building (Figure 1).

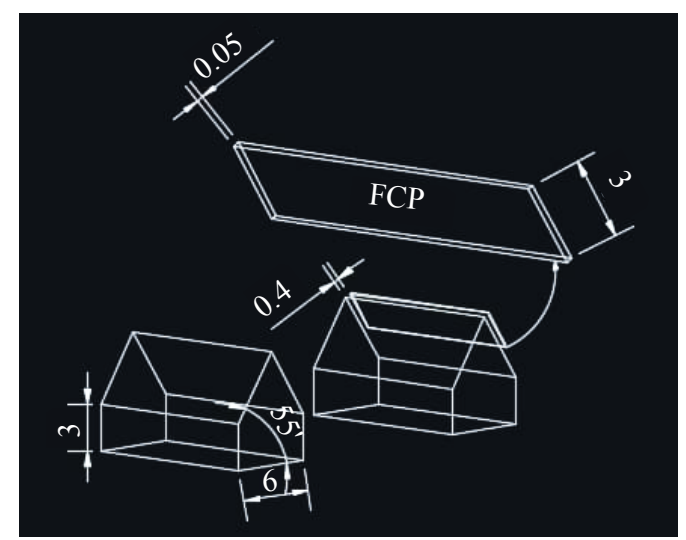

Figure 1. Dimensions and geometrical specifications of the baseline design (left), FCP configuration (right)

Considering the regions, where traditionally such gable roof geometries have been of great interest, such as Europe, Latin America, Russia and parts of Canada, the most generalized and widely used specifications have been chosen for the current research. Such commonalities, the floor numbers, gable roof slope angle and so on, are excessively addressed in architectural standards and handbooks such as Ramsey and Sleeper [25].

The Flow Controlling Plate is installed in a span-wide manner for the top $3 \mathrm{~m}$ of the gable roof length and has an offset distance of $40 \mathrm{~cm}$ off the roof surface. The FCP has been considered to be $5 \mathrm{~cm}$ thick and the upper $10 \mathrm{~cm}$ of its length undergoes a one-sided sharpened half-wedge sub-geometry to prevent the generation of secondary flows of less importance in the concept confirmation process, in the leading edge of the FCP.

\section{Methodology-CFD modelling}

The prime methodology of the current study is the use of CFD for the purpose of numerical investigation of the flow field around the geometry under the certain physical conditions.

The current section of the manuscript presents insight on the strategies and process of the numerical analyses of the flow phenomena. In order to have a physical understanding of the matter, first the mathematical form of the physical equations governing the problem are introduced. These serve as the fundamental principles of the fluid flow. It is going to be followed by a brief discussion on the validity of the chosen numerical modeling approaches for addressing the specific case under study in the current research.

Having covered the fundamentals, the computational domain and its correspondence to the actual physical condition of the case have been discussed under the computational domain and boundary conditions. The atmospheric conditions, the wind flow configuration and intensity, flow alignment and temperature, are the sort of information to be addressed in the boundary conditions sub-section.

Determining the specific physical conditions on the boundary of the solution domain gives one the ability to proceed one step deeper into the procedures of numerical aerodynamics; namely the computational mesh. The mathematical formation of the mesh as well as the distribution of the cells throughout the computational domain have been discussed in the proceeding sub-section, leading to a separate sub-section on independency of the numerical solution to the opted computational grid. The claim of the required independency has been checked by increasing the concentration of the mesh in almost all regions of the domain and comparing the obtained results with those of the previous mesh configurations.

Then, finally the solver and solution methods and specifications have been addressed to precisely define the details of the CFD for the audience.

As mentioned before, all the atmospheric conditions have been simulated for both the base-line design and the FCP 
implemented case, so that the final results could constitute the comparison of the mentioned two sets of flow fields for the purpose of verification of the concept of the FCP.

\subsection{Governing equations}

The behavior of the fluid flow is generally described by the fundamental conservation equations. Among them, the conservation of mass, also known as the continuity equation, conservation of momentum, or the equivalent of the second law of motion stated by Newton, and the conservation of energy, or basically the first law of thermodynamics are of the highest importance (Eqs. 3-1 to 3-4).

The general technical term RANS (Reynolds Average Navier-Stokes) is a fundamental approach addressing the solution of the mentioned governing equations, by averaging the flow properties. However, the more specific term describing the approach opted for this research is U-RANS, where ' $U$ ' stands for the word 'Unsteady'. Since the implementation of an Atmospheric Boundary Layer (ABL) velocity profile on a blunt body which best classifies the case being used in the current manuscript, leads to flow phenomena certainly falling in the unsteady type, the ensemble averaging in URANS will provide the required information as temporal functions suitable for describing the nature of these phenomena $[26,27]$.

$$
\begin{gathered}
\frac{\partial \rho}{\partial t}+\nabla \cdot(\rho \vec{v})=S_{m} \\
\frac{\partial}{\partial t}(\rho \vec{v})+\nabla \cdot(\rho \overrightarrow{v v})=-\nabla \cdot p+\nabla(\vec{\tau})+\rho \vec{g}+\vec{F} \\
\frac{\partial}{\partial t}(\rho H)+\nabla \cdot(\vec{v}(\rho H+\rho))=\nabla \cdot\left(k_{e f f} \nabla T\right)+S \\
=\quad\left[\left[\vec{\tau}=\mu\left[\vec{v}^{T}\right]-\left(\frac{2 \nabla}{3}\right) \cdot \vec{v} I\right]\right.
\end{gathered}
$$

As another layer combined to the equations governing the solution of the case, the $\mathrm{k} \omega \mathrm{SST}$ model is utilized, which is quite known for the aerodynamics analyses of the flow fields with high energy cascade, vorticities and surface dictated streamlinings of high gradients.

This model combines the more commonly used ke model for the less critical regions of the solution domain, with the more physically accurate predictions of model for the high gradient regions (Eqs. 3-5 and 3-6). More in description of the mentioned turbulence models are given by Wilcox [26] and Menter [27]. The transport equations of this model are as shown below;

$$
\begin{gathered}
\frac{\partial}{\partial t}(\rho k)+\frac{\partial}{\partial x_{i}}\left(\rho k u_{i}\right)=\frac{\partial}{\partial x_{i}}\left(\Gamma k \frac{\partial k}{\partial x_{i}}\right)+\overline{G_{\omega}}-Y_{k}+S_{k} \\
\frac{\partial}{\partial t}(\rho \omega)+\frac{\partial}{\partial x_{i}}\left(\rho \omega u_{i}\right)=\frac{\partial}{\partial x_{i}}\left(\Gamma \omega \frac{\partial \omega}{\partial x_{i}}\right)+\overline{G_{\omega}}-Y_{\omega}+D_{\omega}+S_{k}
\end{gathered}
$$

\subsection{Computational domain and boundary conditions}

As the common practice of the discipline numerical building aerodynamics, a log power wind profile (atmospheric boundary layer) has been considered as follows:

$$
U(z)=\frac{U^{*}}{\kappa} \ln \left(\frac{z}{z_{0}}\right)
$$


Where, the values of 0.025 and 0.42 are chosen for the aerodynamic roughness length and von Karman coefficient, respectively [28]. To obtain the friction velocity, $U^{*}$, a reference wind velocity should be used from the statistical weather data, as a known point. Using the five wind classifications based on the Bearfort Scale [29], and their corresponding reference velocities at the measured altitude of $40 \mathrm{~m}$, the values of the friction velocity is calculated, as shown in the Table 1.

Table 1. Bearfort scale categories

\begin{tabular}{cccc}
\hline Bearfort No. & Classification & Upper limit wind speed & Calculated friction velocity \\
\hline I & Light air & $\mathrm{U}(40 \mathrm{~m})=1.5 \mathrm{~m} / \mathrm{s}$ & 0.085 \\
III & Gentle breeze & $\mathrm{U}(40 \mathrm{~m})=5.5 \mathrm{~m} / \mathrm{s}$ & 0.313 \\
IV & Moderate breeze & $\mathrm{U}(40 \mathrm{~m})=7.9 \mathrm{~m} / \mathrm{s}$ & 0.449 \\
V & Fresh breeze & $\mathrm{U}(40 \mathrm{~m})=10.7 \mathrm{~m} / \mathrm{s}$ & 0.609 \\
VI & Strong breeze & $\mathrm{U}(40 \mathrm{~m})=13.8 \mathrm{~m} / \mathrm{s}$ & 0.785 \\
\hline
\end{tabular}

Hence the overall wind velocity profile functions are as follows;

$$
\begin{aligned}
& U_{I}(z)=0.2023 \ln (40 z) \\
& U_{I I I}(z)=0.7452 \ln (40 z) \\
& U_{I V}(z)=1.0690 \ln (40 z) \\
& U_{V}(z)=1.4500 \ln (40 z) \\
& U_{V I}(z)=1.8690 \ln (40 z)
\end{aligned}
$$

For the sake of more clarity, it would be beneficial to introduce the five chosen wind condition categories, to a deeper extent. Starting with the 'Light Air', with the $2-5 \mathrm{~km} / \mathrm{h}$ of wind speed, observable with the use of smoke wind visualization techniques, and causing waves of almost $30 \mathrm{~cm}$ on the sea surface, without the formation of foams on them. Such weather condition is typical for the central European regions being far from the coastal areas of the continent. Parts of Australia and southern states of the US are also considerable for such conditions.

The category entitled 'Gentle Breeze' is known by the characteristic wind speeds of $12-19 \mathrm{~km} / \mathrm{h}$, which would result in roughly $1 \mathrm{~m}$ tall waves on the surface of sea and generates a roughly $1 \mathrm{~Hz}$ tapping sound off the metallic parts of the hung flags and their stand structures. As shown in Figure 2, southern Russia, central-Asia and Northern Africa are subjected to this condition. 


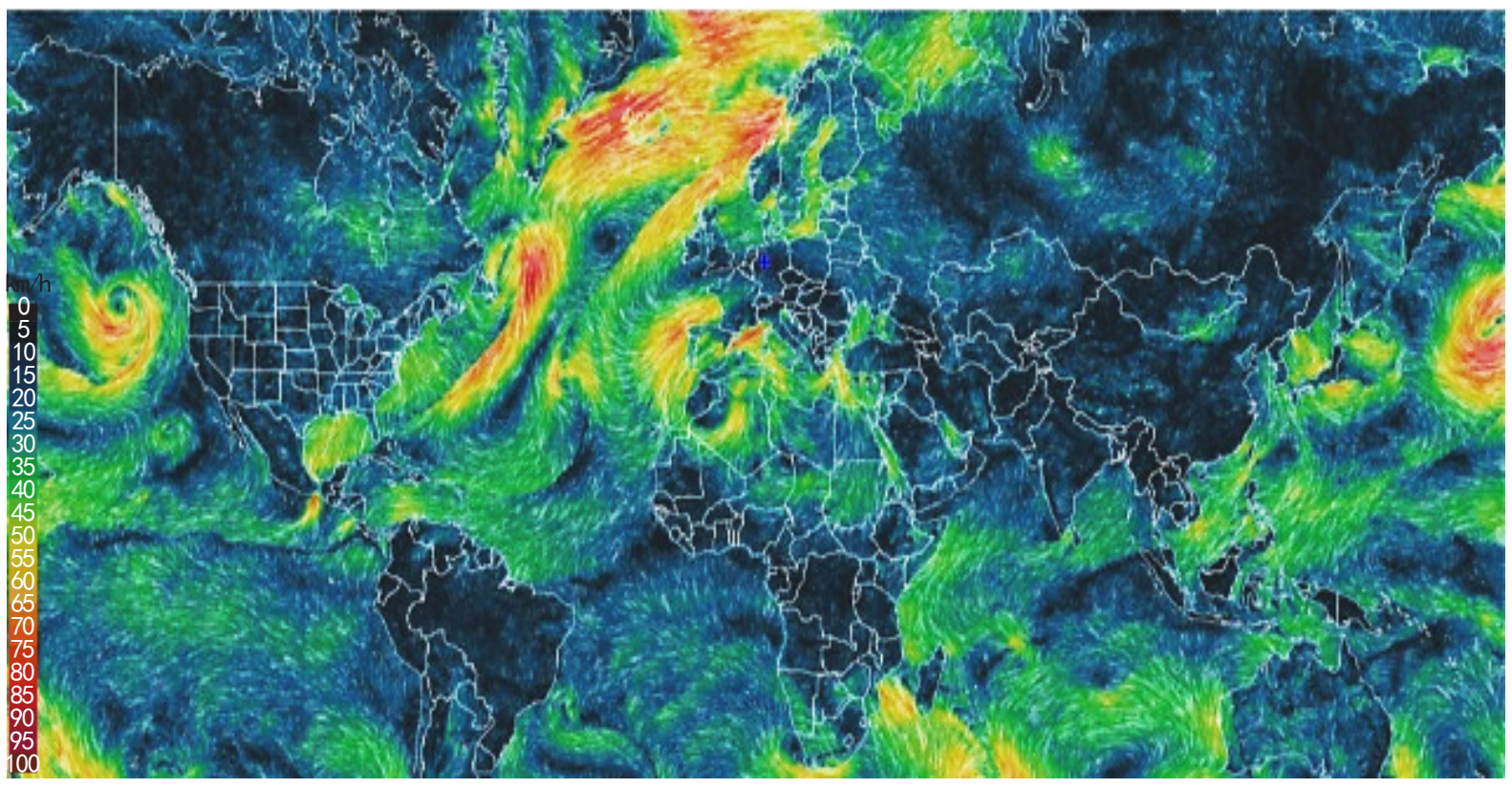

Figure 2. Global wind map, wind velocity on the surface elevation-20.01.2020 [30]

'Moderate Breeze' with the $20-28 \mathrm{~km} / \mathrm{h}$ of wind speeds is the next Beaufort category. And is the type of wind condition which raises dust and loose papers off the ground. Waves generated with this category of wind intensities may rise up to $2 \mathrm{~m}$ in height, and the pieces of land surrounded by sea, such as Italy, Greece, Florida and India, may be the common examples of the moderate breeze on the land.

'Fresh Breeze' is considered to be the wind speeds starting from the upper boundary of the moderate breeze, and up to $38 \mathrm{~km} / \mathrm{h}$, as the next category of 'Strong Breeze' go further to have its the higher range at $49 \mathrm{~km} / \mathrm{h}$ of wind velocity, with the wave heights of 2-3m for the former and 3-4 for the latter case. Fresh breeze is known for the gust of wind loaded with tree leaves and frequent movement of the branches, whereas, the strong breeze is the condition, in which an umbrella is to be used with difficulties. As the last two categories are almost the ones before the emergence of storms, the assessment of the concept of FCP for the sake of energy efficiency through convective heat losses, which are to be implied over a yearly period of time are investigated with wind speeds up to them, to correspond the non-exceptional, normal operation of the gable roof and its enveloping flow fields.

Also, as the architectural center-point of this study has been focused on the low-rise, gable roof geometries, which is certainly the most prominent architectural form of the urban areas in Europe, if not in many other countries all around the world, the above mentioned 5 wind categories are adequately suitable for the study, as shown in Figure 3. 

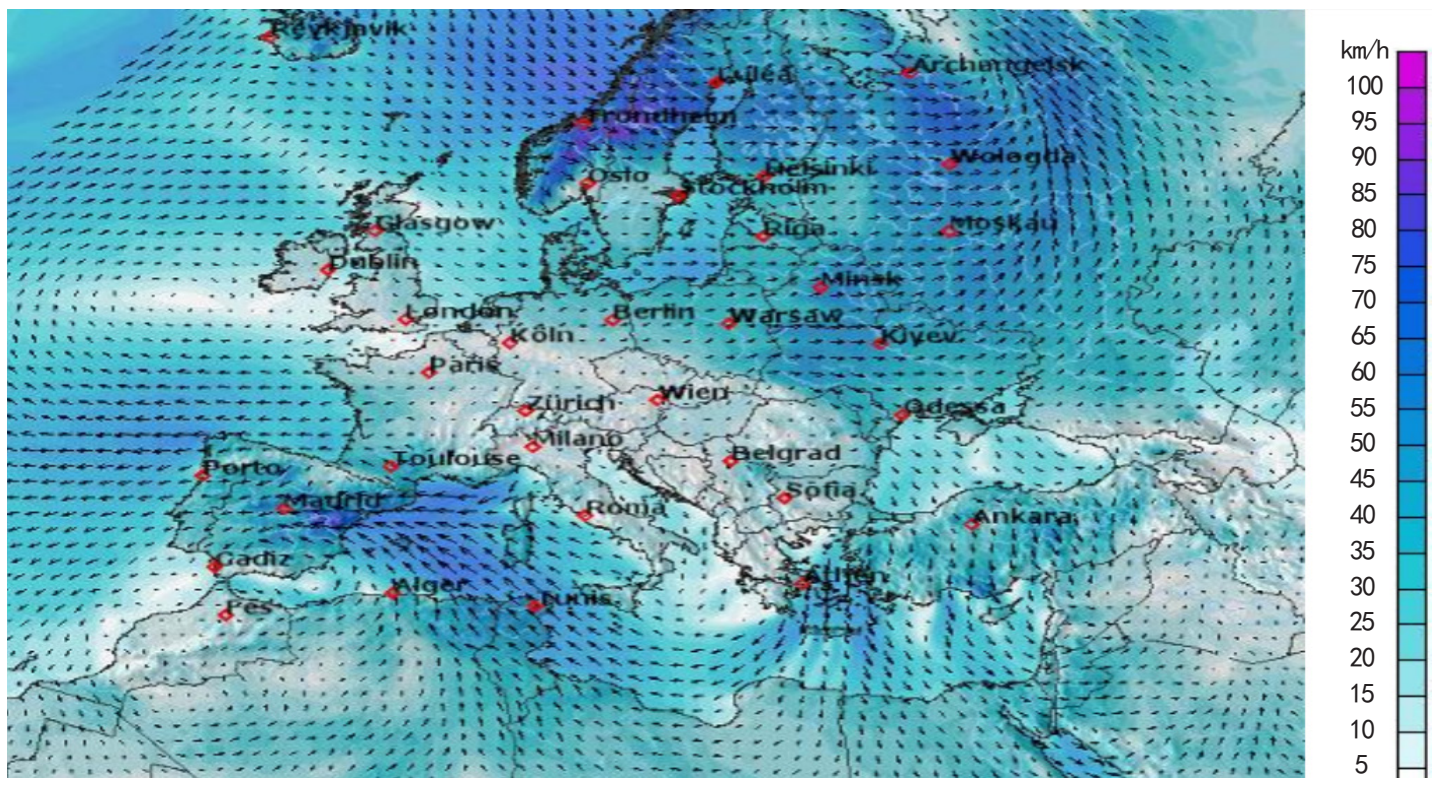

Figure 3. Wind map of Europe, 20.01.2020-16:00 CET [30]

Figure 3 shows the tendency of wind gust to get stronger and more towards the latter two categories discussed above, as one gets closer to the coastal regions of Europe. This is Strongly recognizable in the southern France, North Germany and Spain, as well as Scandinavian countries on the north of Europe.

The Blockage Ratio of the case/domain configuration has been set to the suggested value of $17 \%$ in the vertical direction to obtain the height of the computational domain [31,32], as domain inlet is set to have a 5 and, the outlet a 25 times the characteristics length of the case itself, distance to the case (Figure 4).

$$
B R_{H}=\frac{H_{\text {Building }}}{H_{\text {Domain }}} \leq 17 \%
$$

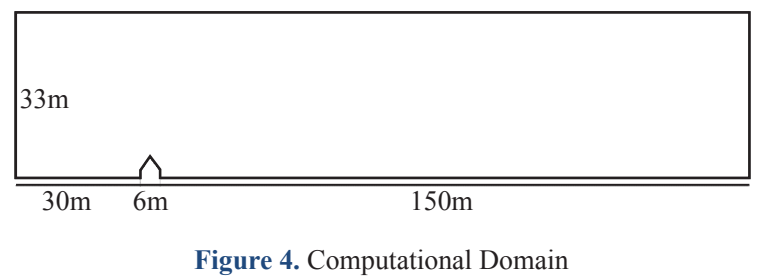

The inlet of the domain is set to be under the premise of velocity inlet with the boundary layer profile as a log power wind profile, whereas the outlet of the domain is considered as a pressure outlet venting to the stationary atmosphere.

Since the thermal behavior and convective heat extraction capacity of the flow is also of great interest to the current research, the temperatures of $296 \mathrm{~K}, 283 \mathrm{~K}$ and $283 \mathrm{~K}$, are considered for the attic room, flow field, and the FCP, respectively. However, since the modification is being primarily done on the leeside of the gable roof, the convective heat transfer coefficient comparisons are going to be reported for that surface only, and not the both sides of the attic. 


\subsection{Numerical grid}

The numerical grid consists of two distinct types of 2D mesh; namely, the boundary layer mesh on the surface near regions, such as the entire geometry of the building and both sides of the FCP, as well as the ground level on the entire domain length, and the unstructured triangular pave mesh cells for the rest of the domain (Figure 5).

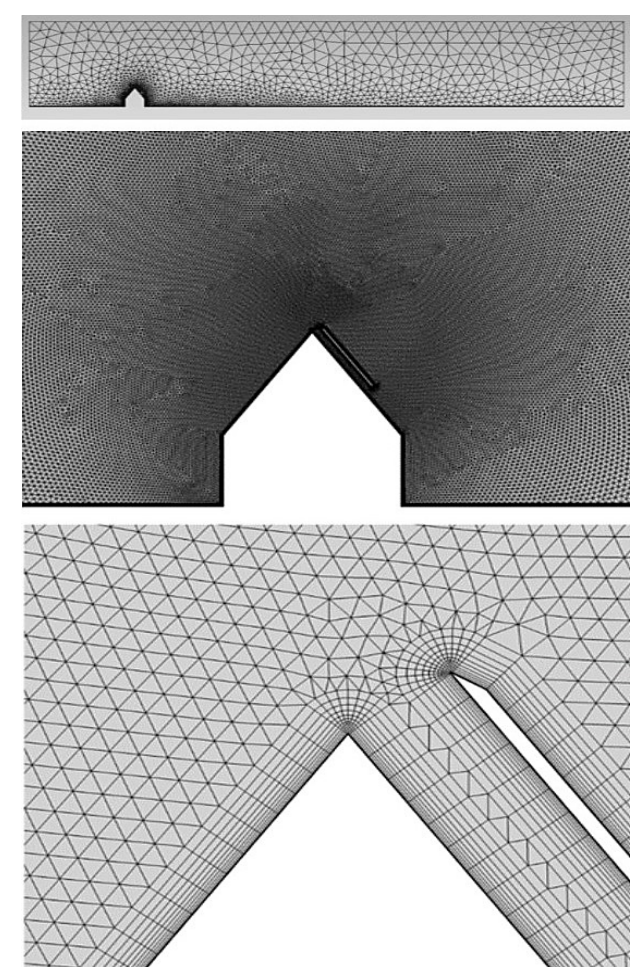

Figure 5. Numerical grid

The boundary layer mesh is calculated to have the normal thickness of $2.7 \mathrm{~mm}$ for its first layer on the surface of the body, which will then continue for 15 more layers with the growth rate factor of 1.2 , while the tangential dimension of the cells on the body is set to be $10 \mathrm{~cm}$ all over the solid surfaces of the domain.

Since the flow analysis has been carried out using the commercial software package Ansys-Fluent, added by the fact that even geometrically structured mesh are seen, and therefore calculated, under unstructured indexing by the embedded algorithms of the code, implementation of unstructured, tri-pave mesh is highly suggested upon and common for such geometries, as the mesh is going to reach a high quality in aspect ratio and skewness, since it will not be forced to abide certain rules to turn to a structured one.

By defining cell dimensions of $4 \mathrm{~m}$ around the domain in the relative far-field, at inlet, outlet and the upper periphery of the domain, the resulting mesh system has turned to include 27732 nodes and 10450 mesh elements.

\subsection{Grid independency study}

In order to verify the independency of the solution to the numerical grid opted for the domain, the mesh concentration on the entire domain has additionally been set with a $33 \%$ increase.

The grid independency has been checked on two criteria, first the convective heat transfer coefficient on the suction side of the gable roof, which has resulted in the mere less than $1 \%$ deviation, as well as the pressure contour of the entire domain, which is visually compared in Figure 6. 


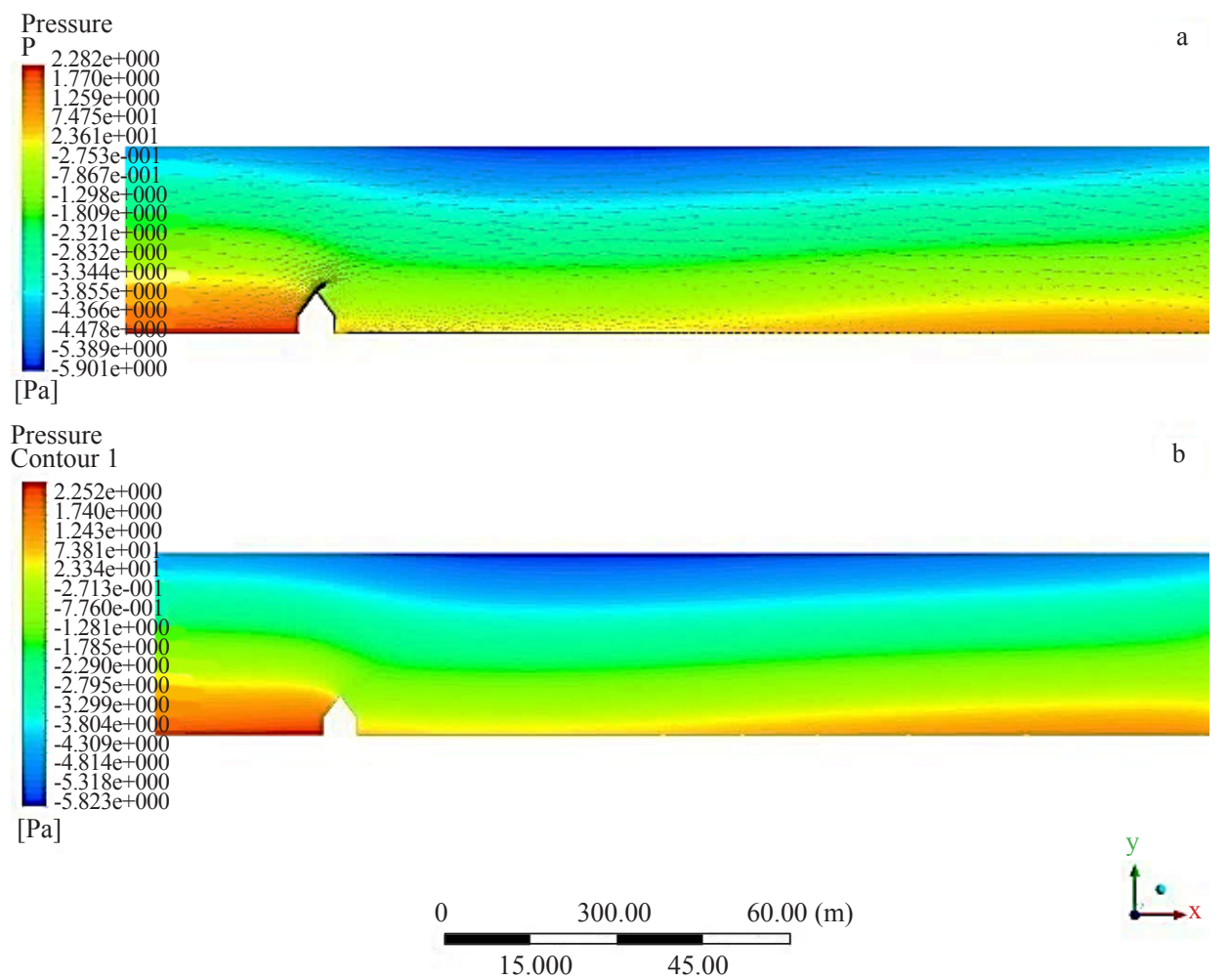

Figure 6. Pressure contours, (a) actual grid, (b) modified grid

\subsection{Solver and solution methods}

The governing equations are discretized by the control volume approach. The "Coupled" algorithm is used to ensure the coupling between velocity and pressure. The rest of the solver and solution features are listed below for a better point-wise understanding of the process:

- Solver type: pressure-based

- Solver time: unsteady

- Simulation duration: $10 \mathrm{~s}$

- Unsteady simulation time steps: $0.05 \mathrm{~s}$

- Finite volume method with a Coupled solver

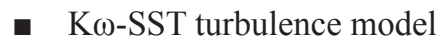

- Enhanced wall for near-wall treatment

- Air density $=1.225 \mathrm{~kg} / \mathrm{m}^{3}$, Const.

- Air viscosity $=1.789 \times 10^{-5} \mathrm{~kg} / \mathrm{ms}$, Const.

- Turbulence Intensity $=8 \%$

- Pressure velocity coupling: Coupled

- Turbulence kinetic energy: second order upwind

- Turbulence dissipation rate: second order upwind

- Momentum: second order upwind

- Energy: second order upwind

- Pressure: standard 


\section{Results and discussion}

The functionality of FCPs has been tested numerically with the purpose of verifying their functionality on a gable roof construction. As the origin of the case introduced and designed in this research has been to address the flow field mostly emerging by the dominance of the atmospheric wind conditions around the gable roof architecture which covers a vast portion of the western urban design, a general representative of the said geometry has been chosen for this study, as well as the atmospheric conditions corresponding to the critical and sub-critical wind gusts blowing towards such areas.

The cases studied are numbers one to five, in an increasing reference velocity of the atmospheric boundary layer considered for the simulations. It is worth mentioning that, of course wind conditions of rather far from critical have also been investigated, the main weight of the study is to justify the effectiveness of the FCP mechanism on the thermal and aerodynamic performance of the building, and more specifically, its gable roof compartment.

The current section provides resulted data and graphical representations on pressure distribution in the entire field, as well as those recorded on the surface mostly super imposed by complete velocity fields to better understand the flow field. Additionally, the turbulence kinetic energy has been introduced in field representation, which gives better understanding of the vorticity field and the capacity of flow to embark on fluctuating, which for a bluff body geometry is considered a prominent and crucial part of the phenomenological approach. The turbulence kinetic energy graphs are mostly super imposed on the mean streamlines of the field, to clearly analyze the region of the flow field corresponding to the vorticities shown by the turbulence kinetic energy values.

Furthermore, tabular data on the convective heat transfer and the drag force representative parameters for the gable roof compartment of the building are presented.

The basic functionality of the FCP concept has been depicted in Figure 7. For this matter the case number 4 has been chosen which corresponds to the inflow condition called fresh breeze [29], with the upper limit wind speeds reaching to $10.7 \mathrm{~m} / \mathrm{s}$ at the standard altitude of $40 \mathrm{~m}$ from the ground surface.

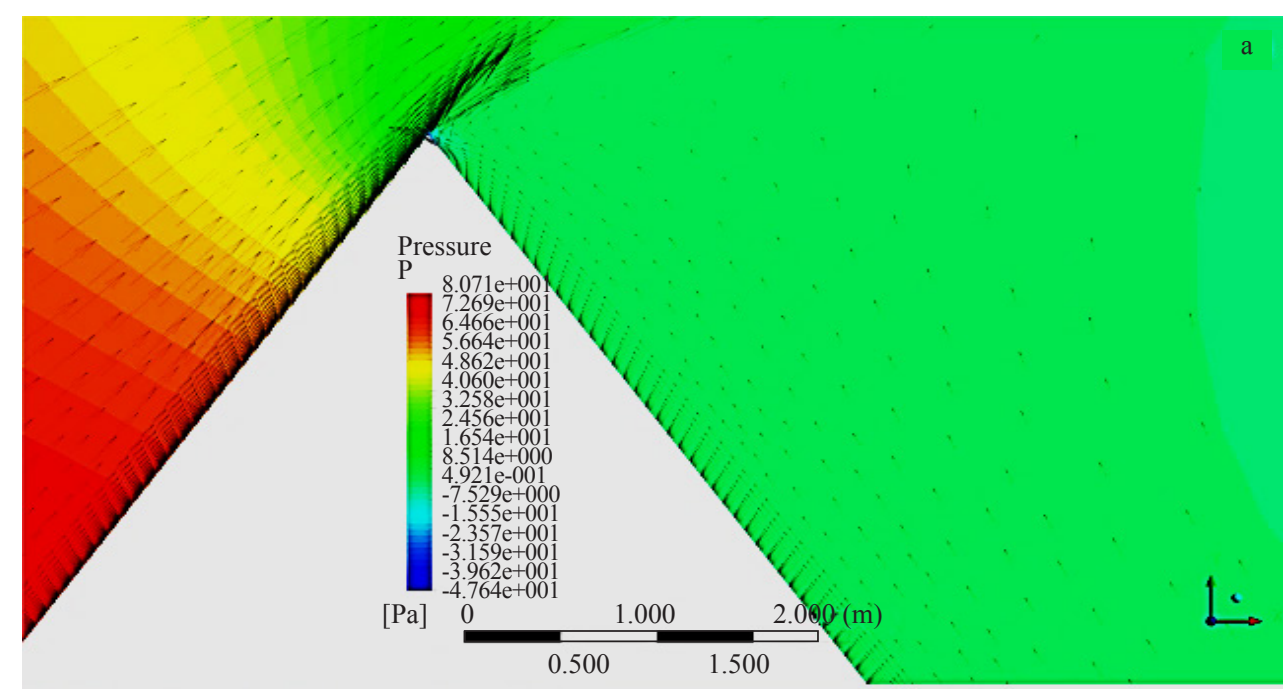




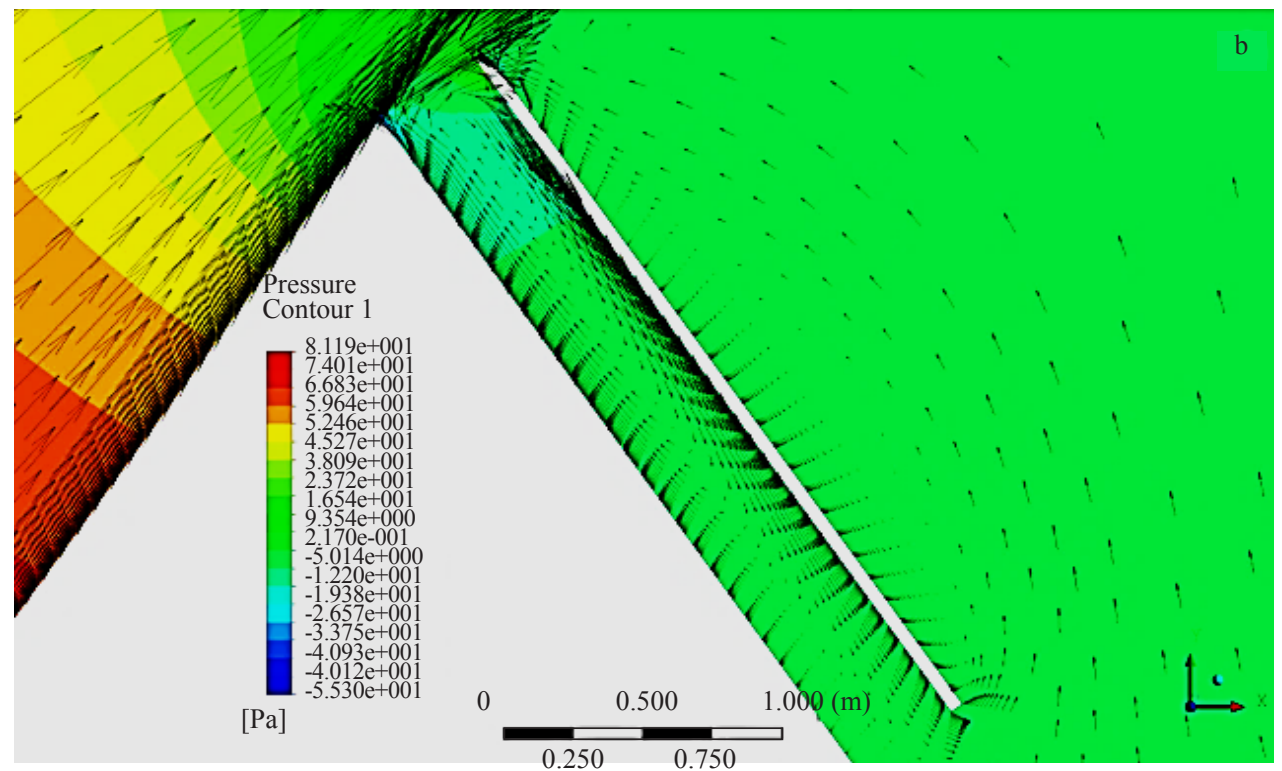

Figure 7. Case 4. Velocity vector field super imposed on the pressure contours-Velocity inlet profile no. V. Fresh Breeze; a) baseline design, b) FCP implemented case

Generally, the sharp discontinuity at the top of the gable geometry certifies a flow separation which by no means turn to be a case of reattachment flow on the mere $6 \mathrm{~m}$ long suction side of the gable roof. This phenomenon puts the whole attic area in a high energy wake region with spectacularly high capacity of forced convective heat transfer, relative to the urban physics cases of comparable size.

The bulk of the flow separated from the geometry at the top corner gets in contact with the much higher layers of the atmospheric boundary layer, exceeding the velocity magnitudes felt by the low height of the building, and bounces back to the low elevation regions. This even increases the convective heat transfer capacity of the flow on the suction side of the gable, as well as the downstream oriented facades of the building.

The described situation with the wake region, its fluctuation to the higher altitudes and diffusion of the momentum and energy from the high velocity layers of the atmospheric boundary layer, could also be translated in the terms of the aerodynamic drag force exerted on the building, and mostly affecting its higher elevations, namely the gable roof facades. This is due to the lower pressure in the wake region and hence the higher-pressure difference between the stagnation areas in the forefront of the geometry and the downstream regions.

In this light, by introducing the concept of the FCP to the lee-side façade of the gable geometry, the first observable phenomenon, also verified by Figure 5b, is the bifurcation of the flow at the top corner of the building, leading to streaming of a part of the flow accelerated over the pressure side, into the channel provided by the FCP geometry.

Therefore, the intensive separation of the entire boundary layer on the top corner of the gable roof is prevented partially as a section of the flow is forced to flow under the FCP. The small distance between the FCP and the lee-side roof provides a forced reattachment of the even small separated flow in the dimensional order of magnitude of the FCP/ roof distance.

The rest of the streamlines flowing over the FCP would first act similar to the baseline design case, as the mere offset of the roof by the added geometry of FCP does not make a difference in this region. However, since the FCP does not represent an internal area with the thermal behavior of the internal zones of the building, the separation over the FCP does not imply a dysfunctional condition.

This is while, the exhausted flow from the end of the FCP diffuses a high momentum over the second part of the surface of the gable roof, and providing the condition for a partial reattachment of the flow separated off the external surface of the FCP. As a result, not only the existence of FCP provides a separation prevention on the first half of the gable roof surface which is under the FCP geometry, but also, the flow condition on the second half of the said surface is improved, although the FCP does not have an active presence on it. 
The further effect is to be witnessed on the downstream vertical facade of the building, as the flow entering the said region is semi-attached, which reduces the intensity of the wake flow on the facade (Figure 8).
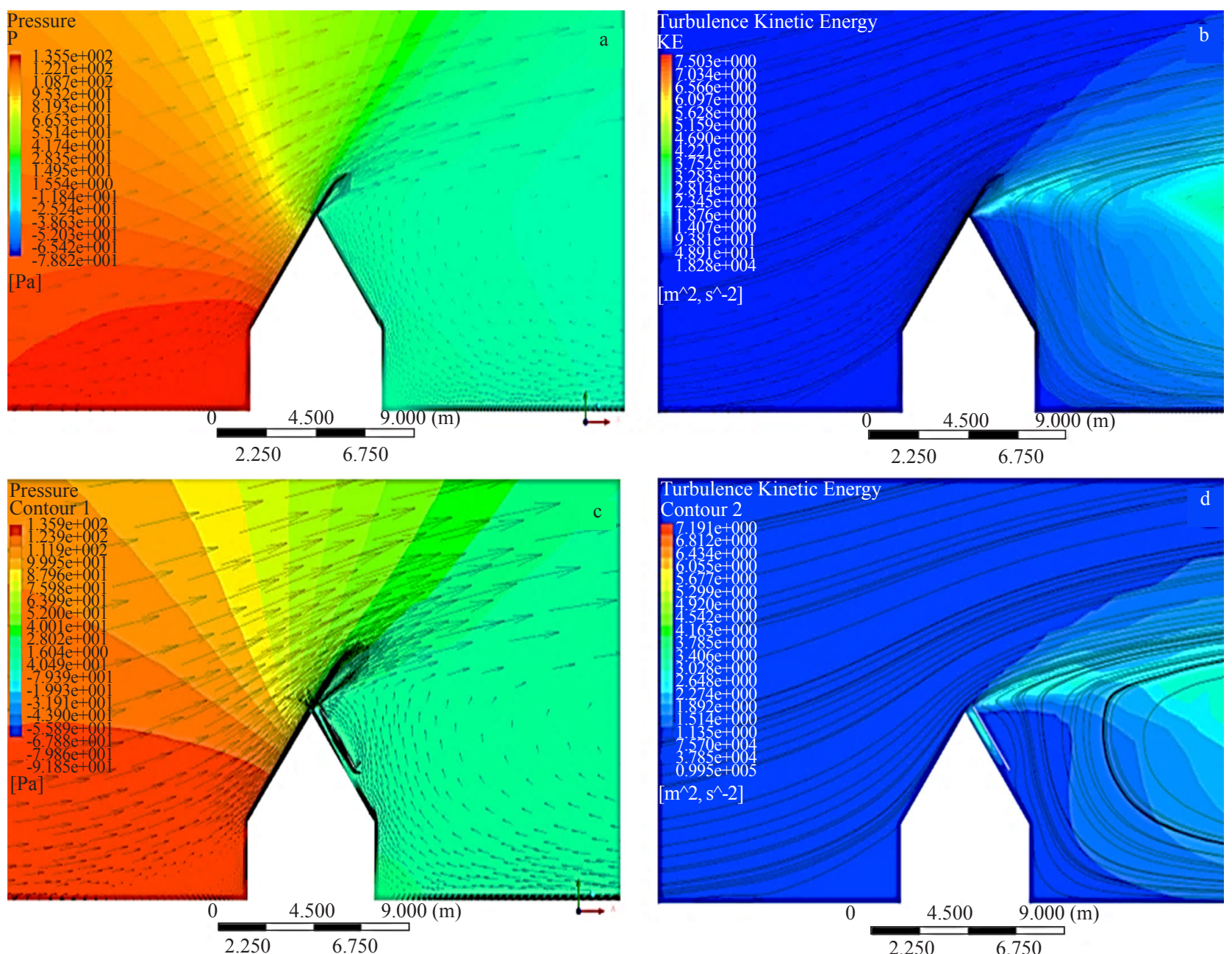

Figure 8. Case 5. Velocity input profile no. VI. Strong Breeze; a) Velocity/Pressure field, baseline design, b) Streamlines and Turbulence Kinetic Energy, baseline design, c) Velocity/Pressure field, FCP implemented case,

d) Streamlines and Turbulence Kinetic Energy, FCP implemented case

Figure 9 provides insight on the whole domain for all five velocity profiles in the baseline design as well as the FCP implemented cases. The pressure contours showing the distribution of the pressure on the geometry, as well as the velocity vector field super imposed on the graphs present the mean velocity field. Additionally, the streamlines are plotted over the turbulence kinetic energy of the entire field for same cases in Figure 10. 

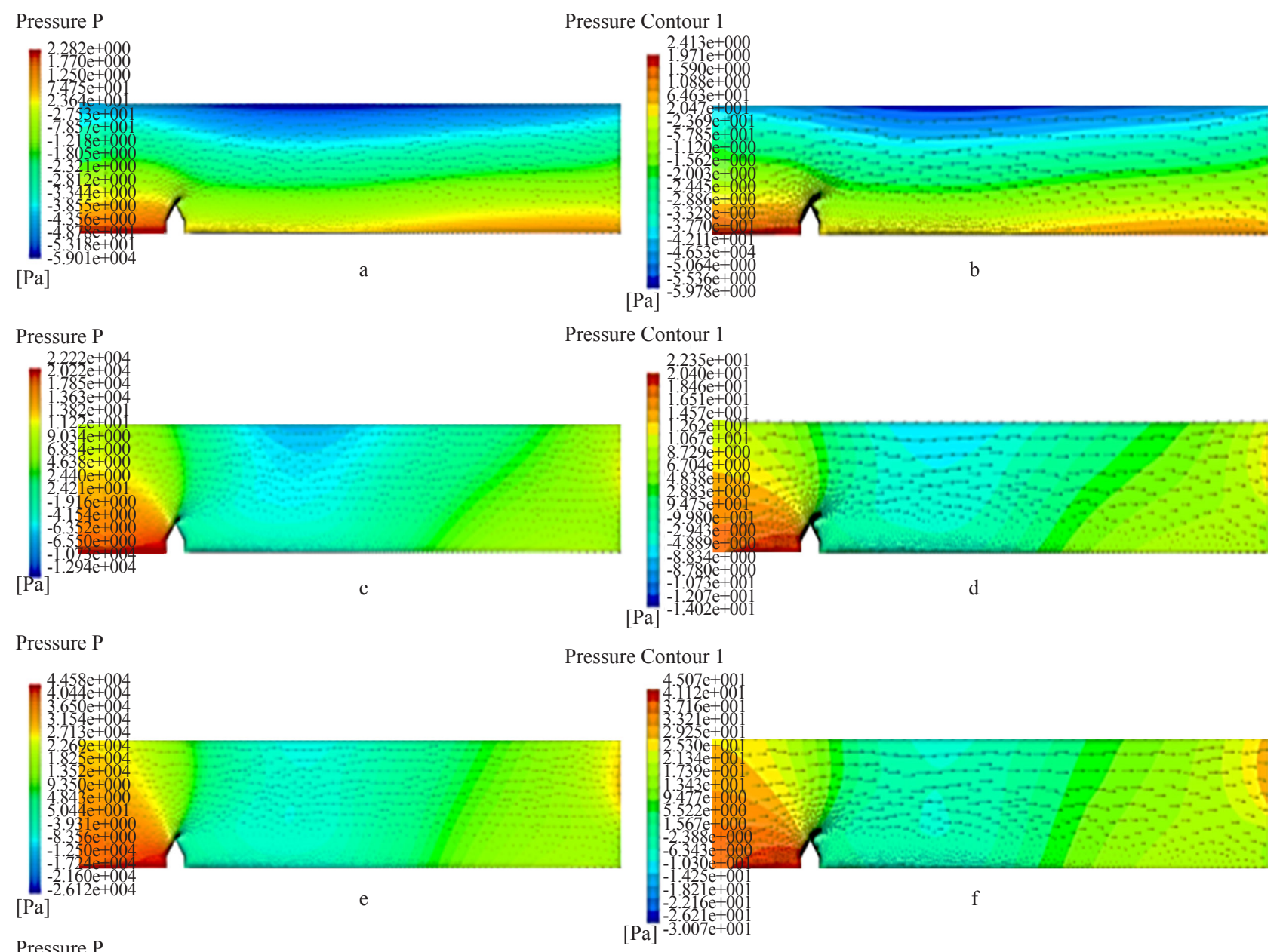

Pressure P

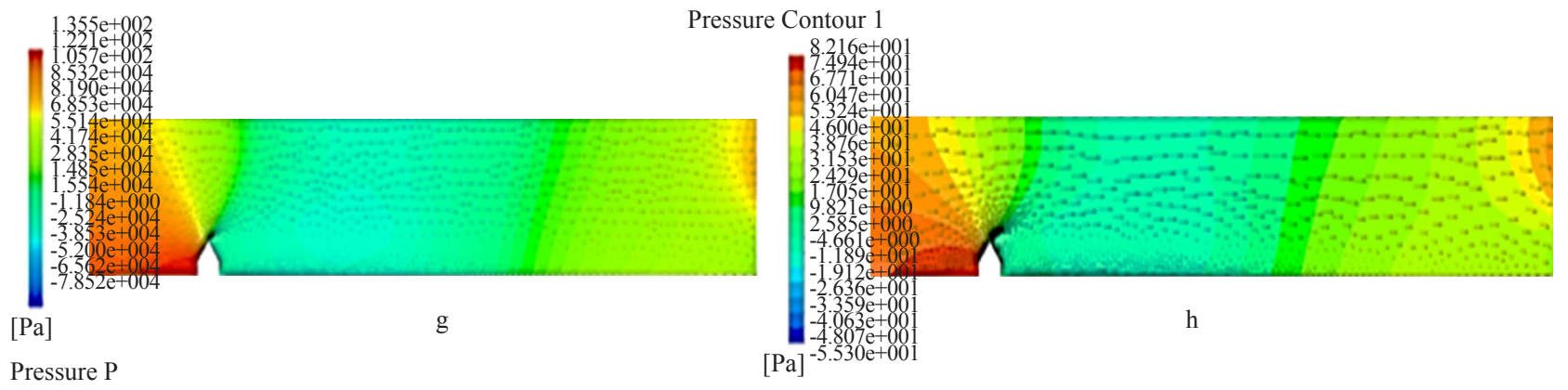

Pressure P

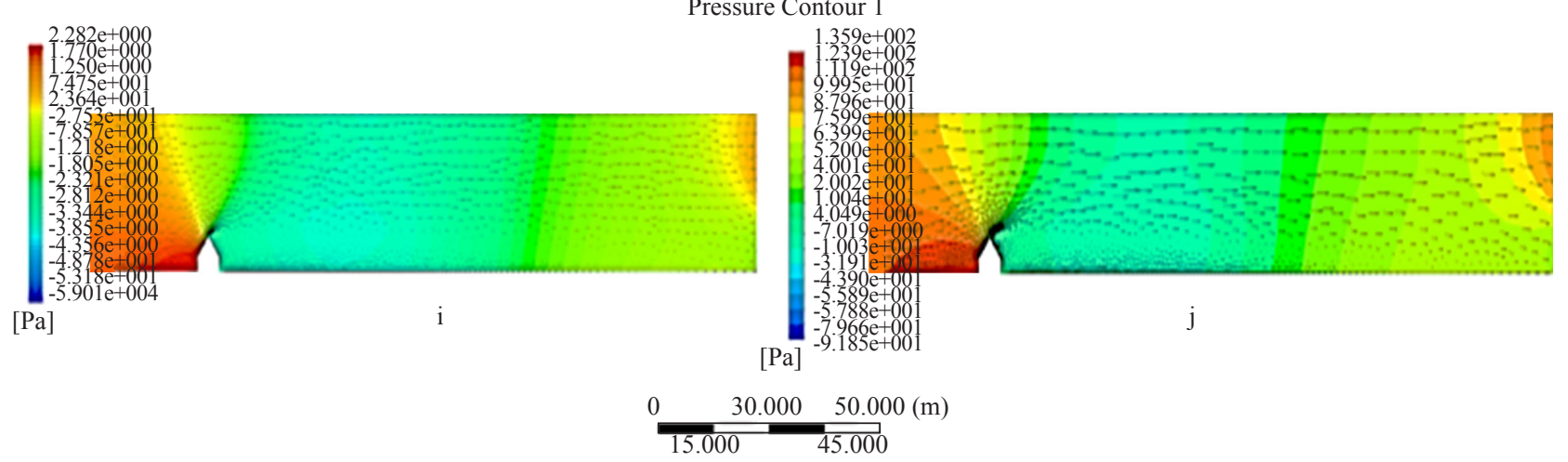

Figure 9. Velocity vector field super imposed on pressure contours; a) Case 1, baseline design, b) Case 1, FCP implemented case, c) Case 2, baseline design, d) Case 2, FCP implemented case, e) Case 3, baseline design, f) Case 3, FCP implemented case, g) Case 4, baseline design, h) Case 4, FCP implemented case, i) Case 5, baseline design, j) Case 5, FCP implemented case 

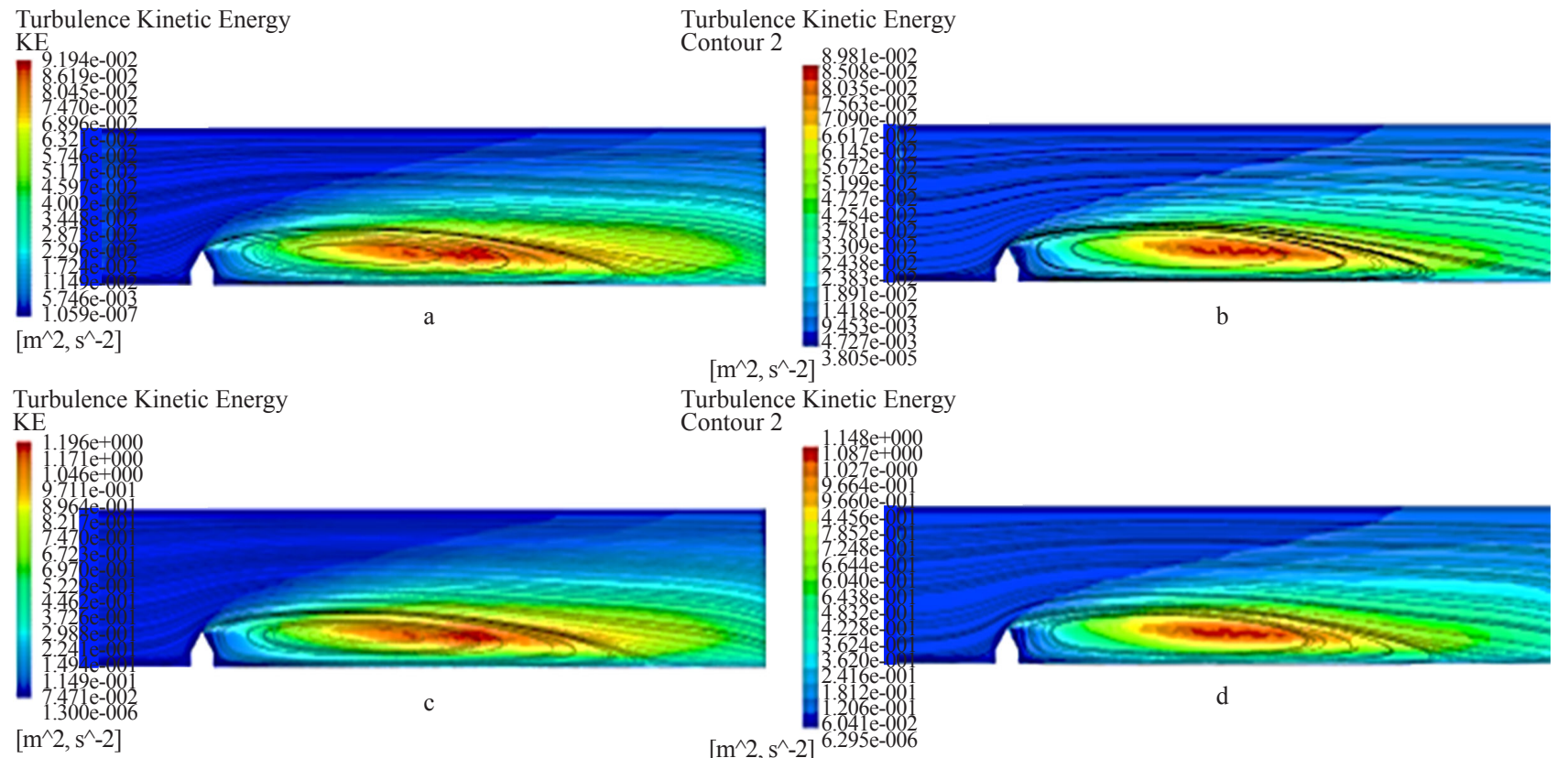
$\left[\mathrm{m}^{\wedge} 2, \mathrm{~s}^{\wedge}-2\right]$

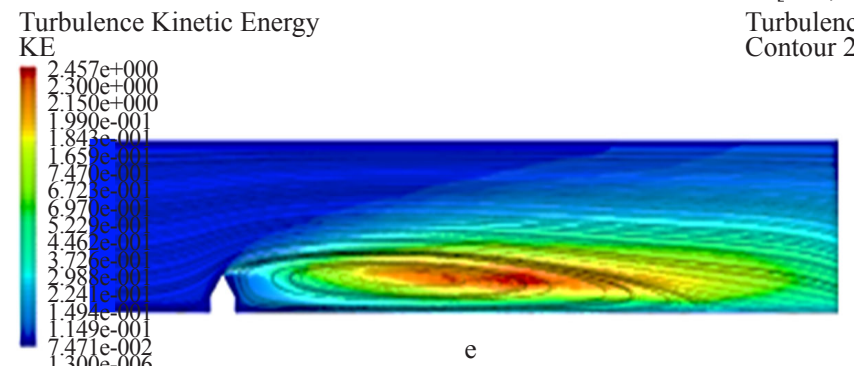
$\left[\mathrm{m}^{\wedge} 2, \mathrm{~s}^{\wedge}-2\right]$

$\left[\mathrm{m}^{\wedge} 2, \mathrm{~s}^{\wedge}-2\right]$

Kinetic Energy
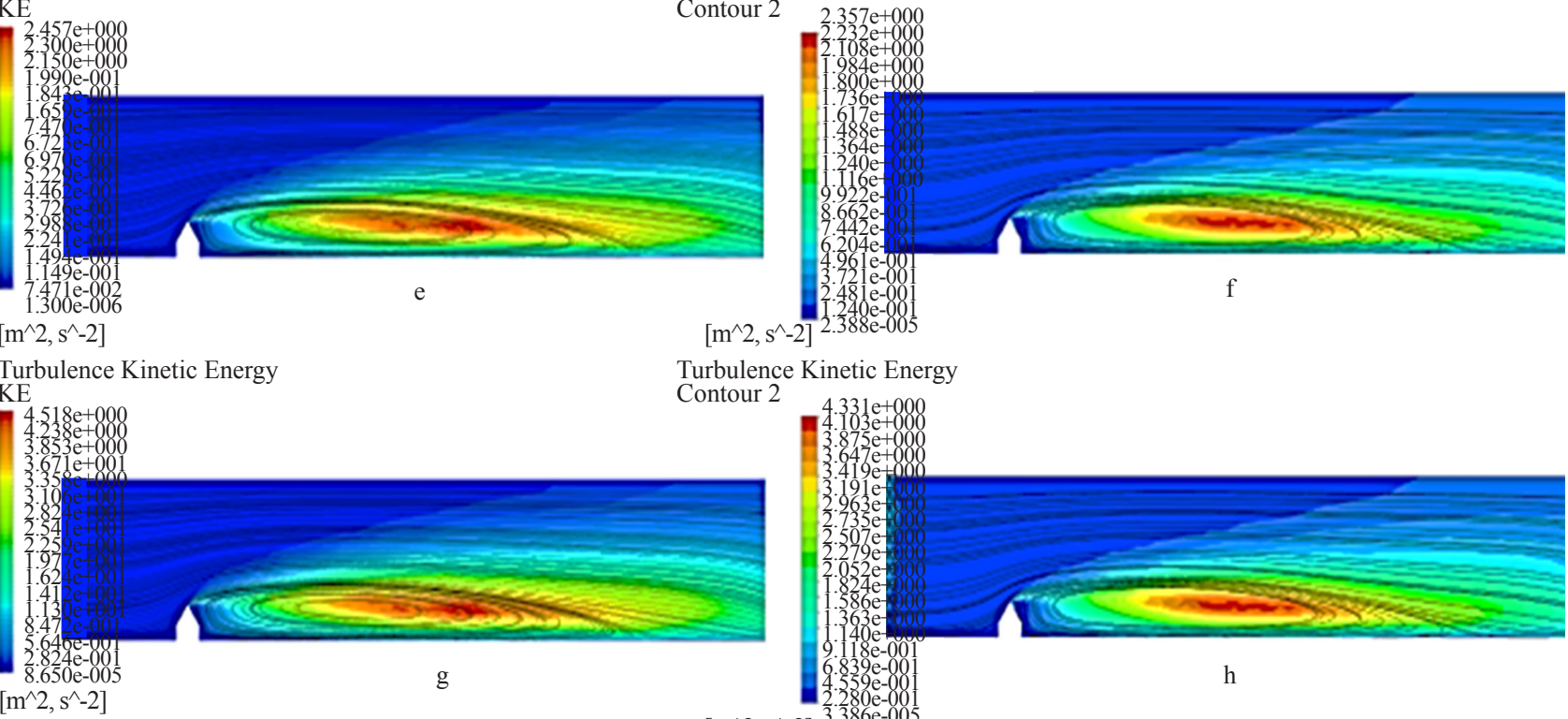

$\left[\mathrm{m}^{\wedge} 2, \mathrm{~s}^{\wedge}-2\right]$
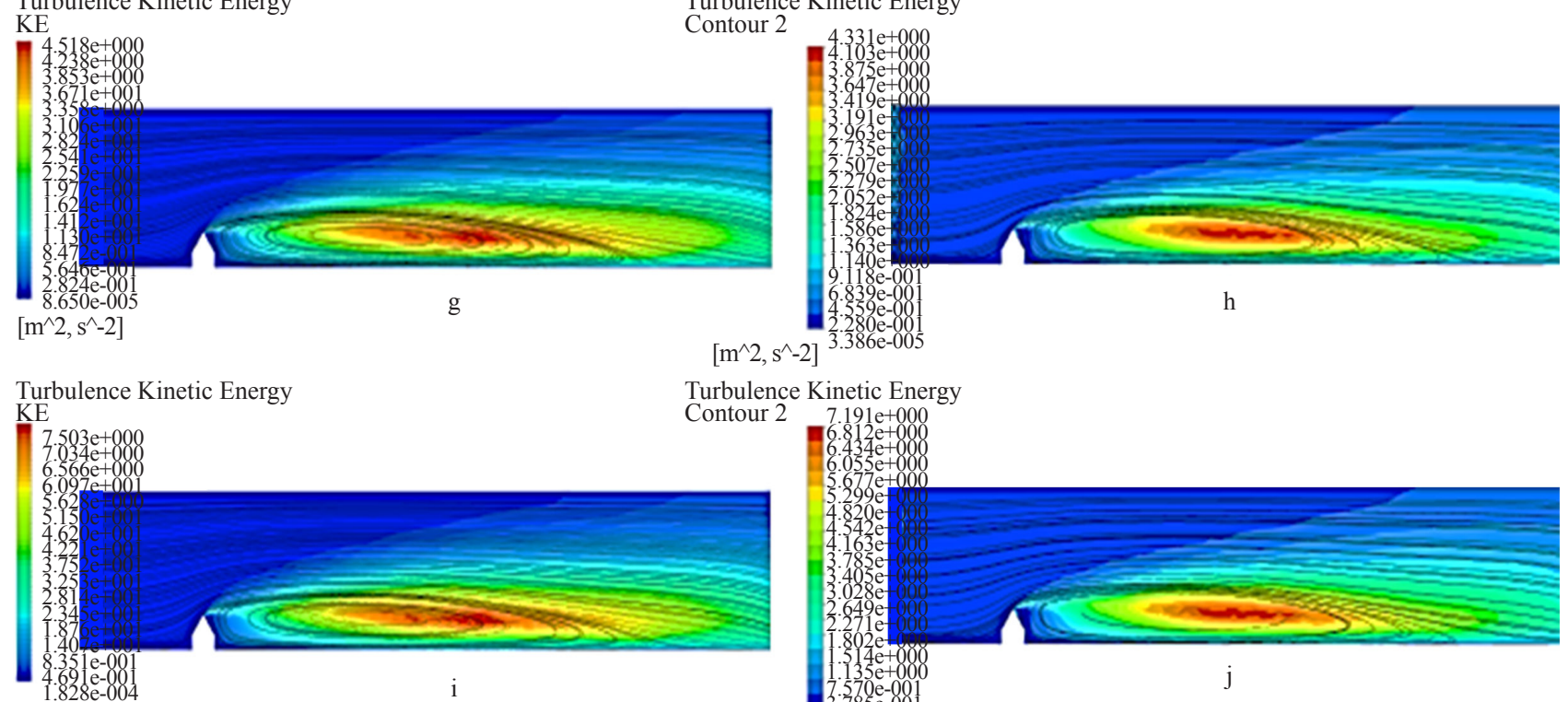

$\left[\mathrm{m}^{\wedge} 2, \mathrm{~s}^{\wedge}-2\right]$

$\left[\mathrm{m}^{\wedge} 2, \mathrm{~s}^{\wedge}-2\right]{ }^{6.995 \mathrm{e}-005}$
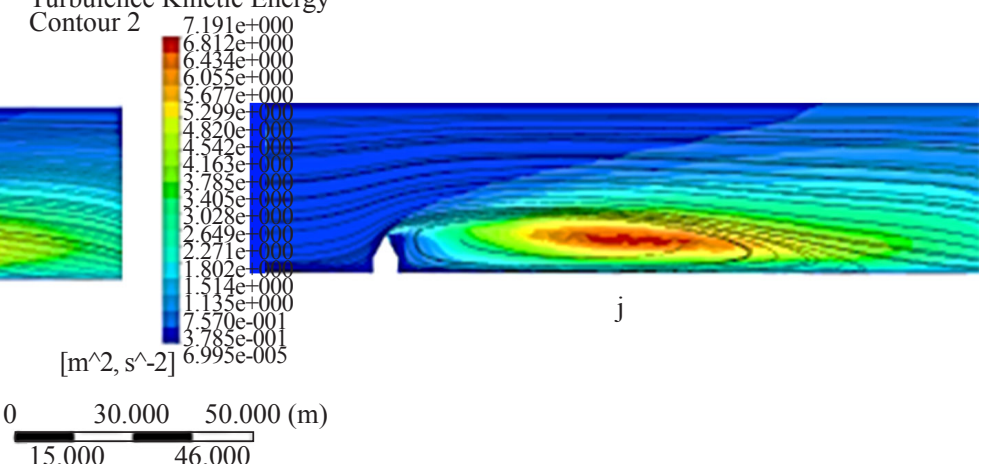

Figure 10. Streamlines super imposed on Turbulence Kinetic Energy contours; a) Case 1, baseline design, b) Case 1, FCP implemented case,

c) Case 2, baseline design, d) Case 2, FCP implemented case, e) Case 3, baseline design, f) Case 3, FCP implemented case,

g) Case 4, baseline design, h) Case 4, FCP implemented case, i) Case 5, baseline design, j) Case 5, FCP implemented case 
The induction of a low-pressure region on the top of the domain, staggered in location downstream the building for the baseline design cases, shows the mixing wake region to be more severe when not using the FCPs (Figure 9c). Also, the more developed nature of the boundary layer formed on the ground downstream of the building on the FCP mounted cases, shows the effectiveness of the flow control, as the less intense wake region on the last façade of the building, from the perspective of the flow, is more likely to be streamlined on the ground, leading to the well developed formation of the boundary layer.

Furthermore, it is perfectly visible that the spots of maximum turbulence kinetic energy are closer to the building in the cases without implementation of the FCPs, and since the length of the domain exceeds $180 \mathrm{~m}$, the displacement of the mentioned flow regions are significant by using the FCPs.

Again, by looking at Figure 9, the height of the wake region, as the region disturbed the most by the existence of the building, is drastically decreased in the cases with FCPs, which extends itself even for a long distance towards the downstream regions of the domain.

Table 2 summarizes the phenomena described briefly above, in a numerical form. The data presented in the table are two-fold; first the values regarding the convective heat transfer coefficient (CHTC) over the entire lee-side of the gable roof have been provided for all velocity profiles and atmospheric conditions, for the baseline design and the FCP implemented cases.

Table 2. Convective heat transfer coefficient and pressure gradient over the gable roof for the base line and FCP implemented cases

\begin{tabular}{ccccccc}
\hline \multirow{2}{*}{ Case no. } & \multicolumn{2}{c}{ CHTC } & \multicolumn{2}{c}{ Pressure Gradient $[\mathrm{Pa}]$} & \multicolumn{2}{c}{ Deviations (\%) } \\
\cline { 2 - 6 } & Baseline Design & FCP implemended & Baseline Design & FCP implemended & CHTC & \multicolumn{2}{c}{$\mathrm{C}_{\mathrm{D}}$} \\
\hline 1 & 13.5292 & 11.9186 & 5.89 & 7.09 & 11.90462 \\
2 & 13.9409 & 11.8241 & 23.07 & 19.32 & 15.1841 \\
3 & 14.928 & 12.323 & 42.71 & 39.08 & 17.45043 \\
4 & 16.7456 & 13.6603 & 74.28 & 53.73 & 18.42454 & 27.66559 \\
5 & 19.1395 & 15.1167 & 137.59 & 114.34 & 21.01831 \\
\hline
\end{tabular}

Then, the pressure difference between the reference points of the pressure- and lee-side of the gable roof are presented, as the reference point being the mid-length of each gable roof facades. This value could trivially represent an index for the drag force (pressure drag) exerted on the gable roof part of the building, whereas, the convective heat transfer coefficient on the surface represents the capacity of the nearby flow field to have thermal interaction with the interior of the building. This could of course be enhanced by addition of the isolation to the façade, however having a less convective flow field near the façade spares the design and construction expenses concerning the isolation. This also could be beneficial when there are openings on the façade for fresh air supplement and/or lighting issues, where no isolation is realizable.

As presented in Table 2, the implementation of FCPs have resulted in the improvement of the thermal condition, namely reducing the value of the CHTC in all cases ranging from $7 \%$ to $21 \%$ in a growing trend depending on the wind speed in far field. The similar trend could be seen for the case of the coefficient of drag, with the improvement of the cases using FCP from near $8 \%$ to $27 \%$ for four of the cases, except the first one. By examining the results closer, one would notice that the insignificant increase of the pressure gradient up to less than $1.5 \mathrm{~Pa}$ has been the reason for such percentile jump on the pressure gradient of the case, which is insignificant as the case corresponds very low inflow velocities, with mere drag forces after all.

\section{Numerical validation process}

It is vitally essential to validate the applied calculation method. By doing so the achieved results of this investigation seem to be more reliable. To do so, either the presented case would be investigated experimentally, or a 
validated similar calculation method could be juxtaposed with the present research. In this section the second choice has been selected.

F. S. Lien et al. [33] have conducted a similar investigation in which a 2D finite volume steady CFD method with a number of variants of the k- $\varepsilon$ turbulence model in boundary layer coupled with SIMPLE algorithm has been applied, to study mean flow and turbulence over a building array in urban area. Through this study the experimental investigations have also been carried out to validate the obtained numerical results. The comparison of predicted and measured stream-wise velocity profiles indicated that the majority of quantitative and qualitative features of the mean flow field, especially around the first building, have envisaged accurately; thus, the mentioned method is reliable enough to be applied in such scopes.

In juxtaposition of this survey and the present research it is plainly visible, that the utilized unsteady calculation, privileged of contemporary $\mathrm{k} \omega$-SST model in vicinity of surfaces and coupled second order algorithm, is more accurate and reliable than the mentioned study. Therefore, this method is also validated to be applied in similar calculations.

\section{Results verification analysis}

K. Ntinas et al. [34] has conducted a 2D CFD study with different turbulence models. Through this study 3 types of buildings, in terms of their roof type, have been simulated and also experimentally tested to assess the quality and accuracy of those turbulence models. Based on the released results of this survey, the k $\omega$-SST turbulence model has an acceptable accuracy to capture the flow field phenomena. In addition, the CFD calculation enjoyed the k $\omega$-SST model has the most precise results in terms of turbulence kinetic energy prediction. If we juxtaposed the published results of this paper and the ones from the present study, it would be plainly visible that both studies have predicted relatively the same angle for the separation of flow field from the pitched-type-roof building (it would be parallel with the roof surface, but with a little downward deviation). The maximum velocity is formed exactly at flow-separation location on pitch point similar to the present study. Notwithstanding, unfortunately the published results of this paper are totally normalized, and we would not leap the chance of quantitative comparison.

Lien [33] has also expressed a range of experimentally validated-2D-CFD results on the wind simulation on array of buildings. Through this research, the inlet velocity profile is totally different with the one applied in the present study. In addition to that the hypothetical considered building is comparatively small; thus, it can be used only for qualitative comparison. It is evident that the quantity of turbulence kinetic energy is increased, as the distance from the ground increases in the wake of the last building, until the center of the vortex. The similar trend is clearly visible in the present expressed results.

Alan Huber [35] in another work, has illustrated a CFD simulation of wind flow over square-shaped buildings and validate the calculations with experimental wind-tunnel measurements. In this paper the magnitude of velocity and consequently the turbulence kinetic energy are so similar with the present research $\left(0.3<\mathrm{TKE}<1.2 \mathrm{~m}^{2} / \mathrm{s}^{2}\right.$ and $-1<$ velocity $<4 \mathrm{~m} / \mathrm{s}$ ). Qualitatively the variations of these parameters are also the same, as mentioned above.

A study, conducted by Andrea de Lieto Vollaro [36], investigates the Heat Transfer Coefficient on external surface of Buildings. This criterion is approximately proportional to the wind velocity and it varies from 3 to $22 \mathrm{~W} / \mathrm{m}^{2} \mathrm{~K}$ with 1 to $8 \mathrm{~m} / \mathrm{s}$ velocity, respectively. This value is similar with the calculated results of the present work.

\section{Conclusion}

The current manuscript addresses the gable roof geometry regarding the strong flow separation on the top corner of the building, leading to a sever flow separation/wake region combination on the flow field, with a major influence on the thermal and aerodynamic performance of the building, specifically the roof area.

The FCP; a thin plate of parallel configuration, has been proposed to be installed on the lee-side of the gable roof façade, with a distance of $40 \mathrm{~cm}$, over the half of the surface of the roof, and tested using an unsteady RANS approach to solve for the flow field around the building.

The outcome results of the 2D CFD, have been presented for the parameters pressure, velocity, turbulence kinetic 
energy, in the utmost applicable fashion for the flow field studies on the bluff bodies, namely the field of building aerodynamics as far as the current research concerns, and being; the superposition of the velocity vector field over the pressure contours as well as the same for the mean streamlines of the flow and the turbulence kinetic energy.

The resulted data on both parameters of the CHTC and $\mathrm{C}_{\mathrm{D}}$ provide overall improvements, as the former shows an average decrease of $16.8 \%$ and the latter is reduced for the average value of $9.8 \%$.

It is worth mentioning, that the current manuscript has dealt mostly on the verification of the concept of FCP, and its advantageous on the flow control over a gable roof geometry. For this reason, a typically designed geometry for the FCP itself, and its relative installation on the gable roof has been chosen and tested in several different weather conditions. However, a further extension on the problem would be to modify and optimize the geometry of FCP itself. One apparent candidate parameter for such modification would be numerical studies of the case with different FCP-roof distances. The non-parallel slope of the FCP to the roof could also be another one, as are numerous other ones.

As far as the common intra and extrapolations would work in science, one could get information regarding the functionality of FCPs in other wind velocities within the range of the wind conditions explored in this paper. The results could also be extrapolated for close divergent neighbors of the said weather conditions outside the range tested here. However, the further conditions oblige extensive investigations of their own to obtain the reliable results.

Such areas could be counted both as the limitations of the current investigation, as well as opportunities for further analyses in the future works and publications.

\section{References}

[1] Castro, I. P., Robins, A. G. Flow around a surface-mounted cube in uniform and turbulent streams. J. Fluid Mech. 1977; 79: 307.

[2] Cermak, J. E. Applications of fluid mechanics to wind engineering-A Freeman Scholar Lecture. J. Fluids Engng. ASME. 1975; 9-38.

[3] Richards P J, Hoxey R P, Short L J. Wind pressures on a 6m cube. J Wind Eng Ind Aerodyn. 2001; 89: 1553-1564.

[4] Richards P J, Hoxey R P. Wind loads on the roof of a 6m cube. J Wind Eng Ind Aerodyn. 2008; 96: 984-993.

[5] Cowan, I. R., Castro, I. P., Robins, A. G. Numerical considerations for simulations of flow and dispersion around buildings. J. Wind Eng. Ind. Aerodyn. 1997; 67(68): 535-545.

[6] Richards P J, Hoxey R P. Pressures on a cubic building-part 1: Full-scale results. J Wind Eng Ind Aerodyn. 2012; 102: $72-86$.

[7] Mirsadeghi, M., Cóstola, D., Blocken, B., et al. Review of external convective heat transfer coefficient models in building energy simulation programs: implementation and uncertainty. Appl. Therm. Eng. 2013; 56: 134-151.

[8] Meinders, E. R. Experimental study of heat transfer in turbulent flows over wall mounted cubes (Ph.D. Thesis). Netherlands: Technische Universiteit Delft; 1998.

[9] Defraeye, T., Blocken, B., Carmeliet, J. Convective heat transfer coefficients for exterior building surfaces: Existing correlations and CFD modelling. Energy Convers. Manag. 2011; 52: 512-522.

[10] Saneinejad S, Moonen P, Defraeye T, et al. Analysis of convective heat and mass transfer at the vertical walls of a street canyon. J Wind Eng Ind Aerodyn. 2011; 99: 424-433.

[11] H. Montazeri, B. Blocken, D. Derome, et al. CFD analysis of forced convective heat transfer coefficients at windward building facades: influence of building geometry. J. Wind Eng. Ind. Aerodyn. 2015; 146: 102-116.

[12] Blocken, B., Stathopoulos, T., Carmeliet, et al. Application of CFD in building performance simulation for the outdoor environment: an overview. J. Build. Perform. Simul. 2011; 4(2): 157-184.

[13] Blocken, B., Janssen, W. D., Van Hooff, T. CFD simulation for pedestrian wind comfort and wind safety in urban areas: general decision frame work and case study for the Eindhoven University campus. Environ. Model. Softw. 2012; 30: 15-34.

[14] Tominaga Y, Mochida A, Yoshie R, et al. AIJ guide lines for practical applications of CFD to pedestrian wind environment around buildings. J Wind Eng Ind Aerodyn. 2008; 96: 1749-1761.

[15] Bottema, M. Wind climate and urban geometry (Ph.D. thesis). Eindhoven University of Technology; 1993.

[16] Kasra Amini, Seyed Mehdi Mortazavi, Elnaz Rezaian, et al. Numerical Investigation on the Convection Heat Transfer and Drag Reduction by Utilizing a Novel Idea of Flow Controlling Blades Designed and Analyzed for a Smart Sustainable House. The journal of Energy Efficiency, Springer. 2019; 12(3): 757-776.

[17] Kasra Amini, Arash Mehrjou, Mahmoud Mani. Enhancing the resolution of the obtained angular orientations of the external flow controlling blades on a sustainable house by training an artificial neural network. The journal of 
Energy Efficiency. 2019.

[18] Shi, X., Zhu, Y., Duan, J., et al. Assessment of pedestrian wind environment in urban planning design. Landscape and Urban Planning. 2015; 140: 17-28.

[19] Reiter, S. Assessing wind comfort in urban planning. Environment and Planning B: Planning and Design. 2010; 37(5): 857-873.

[20] Aregger, H., Glaus, O. Highrise building and urban design. FA Praeger. 1967.

[21] Blocken, B., Carmeliet, J., Stathopoulos, T. CFD evaluation of wind speed conditions in passages between parallel buildings-effect of wall-function roughness modifications for the atmospheric boundary layer flow. J. Wind Eng. Ind. Aerodyn. 2007; 95(9-11): 941-962.

[22] Blocken, B., Stathopoulos, T., Carmeliet, J. Wind environmental conditions in passages between two long narrow perpendicular buildings. J. Aerosp. Eng. ASCE. 2008; 21(4): 280-287.

[23] Stathopoulos, T. Pedestrian level winds and outdoor human comfort. Journal of wind engineering and industrial aerodynamics. 2006; 94(11): 769-780.

[24] Ai, Z. T., Mak, C. M. CFD simulation of flow and dispersion around an isolated building: effect of inhomogeneous ABL and near-wall treatment. Atmos. Environ. 2013; 77: 568-578.

[25] Ramsey, C. G., Sleeper, H. Architectural Graphic Standards (11th edition). New Jersey, USA: John Wiley and Sons, Inc.; 2007.

[26] Wilcox D. Turbulence modeling for CFD. La Canada: DCW Industries; 2006.

[27] Menter F. Two-equation eddy-viscosity turbulence models for engineering applications. AIAA J. 1994; 32(8):15981605.

[28] Wieringa, J. Updating the davenport roughness classification. J. Wind Eng. Ind. Aerodyn. 1992; 41: 357-368.

[29] National Meteorological Library and Archive Fact sheet 6-The Beaufort Scale. Archived from the original on 2 October 2012. Retrieved 13 May 2011.

[30] Meteoblue interactive wind movie-meteoblue. https://www.meteoblue.com/en/weather/maps/index/paderborn germany_2855745\#51.719N8.754E_CET+01:00_10.0_wind_surface_pause_1579478400_1579532400.

[31] Blocken, B. Computational fluid dynamics for urban physics: Importance, scales, possibilities, limitations and ten tips and tricks towards accurate and reliable simulations. Build. Environ. 2015; 91: 219-245.

[32] Casey M, Wintergerste T. Best practice guidelines, ERCOFTAC special interest group on quality and trust in industrial CFD. Brussels: ERCOFTAC. 2000.

[33] F. S. Lien, E. Yee, Y. Cheng. Simulation of mean flow and turbulance over a 2D building arrey using highresolution CFD and a distributed drag force approach. Journal of wind engineering and industrial aerodynamics. Elsevier, 2004; 92: 117-158.

[34] Georgios K. Ntinas, Xiong Shen, Yu Wang, et al. Evaluation of CFD turbulence models for simulating external airflow around varied building roof with wind tunnel experiment. Research Article Indoor/Outdoor Airflow and Air Quality. 2018; 11(1): 115-123.

[35] Alan Huber, Wei Tang, Anita Flowe. Development and Applications of CFD Simulations in Support of Air Quality Studies Involving Buildings. 13th Joint Conference On The Application Of Air Pollution Meteorology. Vancouver, BC, Canada, American Meteorological Society, Boston, MA and Air and Waste Management Association, Pittsburgh, PA; 2004. p. 7.

[36] Andrea de Lieto Vollaro, Giorgio Galli, Andrea Vallati. CFD Analysis of Convective Heat Transfer Coefficient on External Surfaces of Buildings. Sustainability. 2015; 7(7): 9088-9099. 